\title{
Transtoracical Ecocardiographic Assessment of Severe Degenerative Aortic Stenosis with Normal Ejection Fraction and Low Transvalvular Gradient
}

\author{
IOAN TIBERIU NANEA ${ }^{1}$, CAMELIA NICOLAE ${ }^{1}$, ADRIANA MIHAELA ILIESIU ${ }^{1}$, FLORENTINA CRISTINA PLESA ${ }^{2}$, LIANA PLES ${ }^{1}$, \\ ALICE MUNTEANU², MAGDALENA DIACONU ${ }^{3}$, ALINA BISOC ${ }^{4 *}$, CONSTANTIN CIUCUREL ${ }^{5}$, ELENA IOANA ICONARU5, \\ ALINA PAUNESCU ${ }^{5}$ \\ ${ }^{1}$ Carol Davila University of Medicine and Pharmacy, 8 Eroii Sanitari Blvd., 050474, Bucharest, Romania \\ ${ }^{2}$ Titu Maiorescu University of Bucharest, Faculty of Medicine, 22 Dambovnicului Str., 040441, Bucharest, Romania \\ ${ }^{3}$ University of Medicine and Pharmacy Craiova, 2 Petru Rares Str., 200349, Craiova, Romania \\ ${ }^{4}$ Transilvania University of Brasov, Faculty of Medicine, 29 Eroilor Blvd., 500036, Brasov, Romania \\ ${ }^{5}$ University of Pitesti, Faculty of Sciences, Physical Education and Informatics, 1 Targu din Vale Str., 110040, Pitesti, Romania
}

Purpose of the study: echocardiographic evaluation of the form of degenerative aortic stenosis (DAS) with preserved ejection fraction (EF) and low transvalvular gradient, in order to formulate the indication of valvular prosthesis as early as possible; retrospective observational study that includes patients admitted or sent for ambulatory evaluation by other medical services. The echocardiographic parameters used: systolic and diastolic indices, tissue and spectral, mitral and tricuspid veins, aortic orifice area, maximal aortic systolic velocity, maximal and medium aortic transvalvular gradient, myocardial mass index, volume of left atrium, left ventricular (LV) thickness. 42 patients with severe DAS and preserved EF, average age $71.7 \pm 3.85$ years. Two groups were isolated: $A$ - with increased gradient (22 patients) and B - with low gradient (20 patients). The gender distribution was comparable: women representing 33\% in group A versus $30 \%$ in group $B$. The average age of women in both groups was higher than that of the men: in group A: $72 \pm 8$ years in the case of women vs. $67 \pm 6$ years in the case of men and in group $B 72 \pm 3.5$ years in women vs. $68 \pm 6$ years in men. Apical displacement of the mitral ring: $14 \pm 2 \mathrm{~mm}$ in lot $A$ vs. $11 \pm 2 \mathrm{~mm}$ in lot B. Myocardial mass index: $120 \pm 9 \mathrm{~g} / \mathrm{m}^{2}$ in lot $A$ vs. $126 \pm 12 \mathrm{~g} / \mathrm{m}^{2}$ in lot $B$. Left ventricular filling ratio $E / e^{\prime}: 8 \pm 2$ in lot $A$ vs. $13 \pm 2$ in lot $B$; maximum aortic systolic velocity: $4.3 \pm 0.9 \mathrm{~m} / \mathrm{s}$ in lot $A$ vs. $3.1 \pm 0.8 \mathrm{~m} / \mathrm{s}$ in lot $B$; maximum gradient: $73.9 \pm 10 \mathrm{mmHg}$ in lot $A$ vs. $37 \pm 12 \mathrm{mmHg}$ in lot $B$; aortic orifice area: $0.80 \pm 10.5 \mathrm{in} \mathrm{lot} A$ vs. $0.79 \pm 0.07$ in lot $B$. Statistical analysis shows the Pearson correlation index $r$ with the highest values of $95 \%$ at the significance threshold between the aortic orifice area and the valve opening $(r=0.87)$, the ratio E/e' $(r=-$ $0.85)$ and diastolic thickness of the posterior wall of the aortic left ventricle $(r=0.78)$. Aortic stenosis with preserved ejection fraction and low gradient was more common in men. The filling ratio $E / e^{\prime}$ was increased $(13 \pm 2)$ in group $B$, suggesting the increase of filling pressures of $L V$ in patients with DAS and low transvalvular gradient. Tissue spectral systolic and longitudinal velocities were lower in group $B$, suggesting the onset of systolic LV dysfunction. The aortic valve opening and the E/e' ratio showed the highest correlation coefficient with the area of the aortic orifice in both groups. The myocardial mass index and the thickness of the walls of the LV cavity are similar in the two groups, suggesting that the reduction of the LV cavity through hypertrophy may not explain, at least in totality, the form of DAS with low gradient and preserved ejection fraction.

Keywords: degenerative aortic stenosis, transvalvular flow, ejection fraction, gradient, orifice area

Degenerative aortic stenosis is defined by Catherine 0 tto [1] as a slowly evolving disorder, which induces negative hemodynamic effects and causes symptoms by progressive obstruction of the left ventricular ejection tract. According to the currentstatistical data [2,3], after 65 years of age, $2 \%$ of the population presents aortic stenosis by valvular calcification and $30 \%$ aortic sclerosis, this being defined as an irregular thickening of the aortic valves, detected echocardiographically, without significant limitation of the mobility of the cusps. After 90 years the prevalence of aortic stenosis is $9.8 \%$. [4]

The mechanisms involved in the pathogenesis of the disease are complex [5-9] and are generally similar to atherosclerosis. From the perspective of the present data, however, specific pathophysiological processes such as ossification are also detected. The main processes are lipid infiltration, inflammation and calcification, followed by limitation of valvular mobility, but, unlike the mechanism of rheumatic aortic stenosis, no commissural damage occurs. It is thus appreciated that in the presence of favorable environmental and clinical factors, such as the male gender, diabetes mellitus, hypercholesterolemia, smoking, under the action of hemodynamic stress and vascular endothelial insufficiency, the oxidation and deposition of lipids in the subendothelial structures are involved $[10,11]$. Stimulation of monocytes and macrophages is followed by the release of inflammatory factors and the transformation of fibroblast into osteoblast with bone tissue production and calcification.

The onset of symptoms in DAS is recorded around the age of 60 in the case of genotype 1, considered of high risk, and around the age of 80 years in the case of genotype 2, considered of low risk. It is estimated that the onset of angina limits the life expectancy to 5 years and the symptoms of heart failure to 2 years. From this point of view, the evaluation of the cardiac function and the detection of the onset of the systolic dysfunction of the left ventricle could bring benefits in the prognosis of the disease 
by the earlier formulation of the indication of surgical valvular replacement [12-14].

The current guidelines stage aortic stenosis from the perspective of the aortic orifice area, in the context of a normal or low ejection fraction. Severe aortic stenosis is rated at less than $1 \mathrm{~cm}^{2}$ or $0.6 \mathrm{~cm}^{2} / \mathrm{m}^{2}$ if indexed to body surface area. Useful additional criteria in assessing the severity [15-17] of aortic stenosis are maximal and transvalvular systolic velocities and gradients are maximum and medium. In the presence of an ejection fraction greater than $50 \%$, the severity of aortic stenosis is estimated to be greater than $4 \mathrm{~m} / \mathrm{s}$ of maximal transaortic systolic velocity and at an average systolic pressure gradient greater than $40 \mathrm{mmHg}$.

The installation of left ventricular systolic dysfunction (LV) alters the values of transvalvular velocities and gradients, so that low systolic flow through the aortic orifice can be encountered in both the presence of severe aortic stenosis and moderate stenosis [18-20]. In this situation, performing the pharmacological stress test with dopamine may unmask the presence of a severe stenotic lesion if the aortic orifice area increases and the systolic velocities increase, too [21].

The literature [3,22-29] describes the existence in the group of severe aortic stenosis with preserved ejection fraction, of a subgroup of patients with aortic orifice area less than $1 \mathrm{~cm}^{2}$, but who present maximal transvalvular systolic velocities lower than $4 \mathrm{~m} / \mathrm{s}$ at the echocardiographic evaluation. According to these studies, the explanation of the phenomenon would mainly consist of the existence of important concentric left ventricular hypertrophy that associates a small ventricular cavity and a low systolic flow. [30]

The purpose of this study is to evaluate the significance of the low systolic aortic transvalvular gradient in patients with severe degenerative aortic stenosis and preserved ejection fraction, in order to formulate the indication of valvular prosthesis as early as possible.

\section{Experimental part}

Patients referred for ambulatory evaluation or admitted to the Cardiology and Internal Medicine clinics of the PhD.Theodor Burghele Hospital in Bucharest, Romania were included in the study, respecting the ethical norms regarding the research and confidentiality of personal data $[31,32]$. The inclusion criteria in the study were severe degenerative aortic stenosis and EF greater than $50 \%$. Exclusion criteria were: aortic/rheumatic stenosis, moderate-severe associated valvulopathies, ischemic coronary disease, acute coronary syndromes, primitive pulmonary hypertension, rhythm and conduct disorders, absence of sinus rhythm, primary and/or secondary sinus disease, pericarditis, oncological diseases during chemotherapy, [33] heart, respiratory and renal failure, [34] hemoglobin less than $10 \mathrm{~g} / \mathrm{dL}$ [35], decompensated metabolic diseases, presence of skin lesions, with overadded infections or multi-resistant germ infections [3644]. The patients were evaluated clinically and paraclinically, it was noted the presence of cardiovascular risk factors, the presence of symptoms, and pharmacological treatment given to the patients. The echocardiographic parameters used for the study were obtained by transthoracic approach using the Aloka Prosound SSD 400 device. The calculation of each echocardiographic parameter was obtained by averaging five determinations. Their normal limit value was established in accordance with the current published documents [45].
The thickness of the LV walls was obtained using the parasternal longitudinal section, mode $M$. The volume of the left atrium (Vol.LA) was obtained in the apical section, at the end of the systole, electrocardiographically marked by $R$ wave. The volume $M$ of the left atrium greater than $50 \mathrm{~mL}$ in women and $60 \mathrm{~mL}$ in men was considered normal.

Myocardial mass (MM) was considered normal up to $160 \mathrm{~g}$ in women and $220 \mathrm{~g}$ in men; the indexed values (IMM) on the body surface were maximum $95 \mathrm{~g} / \mathrm{m}^{2}$ in women and $115 \mathrm{~g} / \mathrm{m}^{2}$ in men.

For the calculation of MM the formula Devereaux was used:

$M M=0.8\{1.04[($ LVEDD+IVSd + PW d ) 3"LVEDD3 $\}+0.6$, with:

LVEDD $=$ diastolic diameter of the left ventricle in the telediastole

IVSd= thickness of the interventricular septum in diastole

PWd = thickness of posterior wall of left ventricle in diastole

The diastolic function of LV was evaluated using the spectral and tissue anteroposterior mitral Doppler parameters A and E respectively $e^{\prime}$ and a'. Apical displacement of the lateral mitral ring (MAPSE) was used as an indicator of the longitudinal systolic function of LV and was considered to have a normal value greater than $12 \mathrm{~mm}$. Systolic tissue parameters of LV (sLV) and diastolic $e^{\prime}$ and ' $a^{\prime}$ represented the average of the values obtained by interrogating the medial and lateral mitral ring. The average value greater than $0.09 \mathrm{~cm} / \mathrm{s}$ of $\mathrm{sLV}$ was appreciated as normal.

The longitudinal function of the right ventricle was assessed using the systolic apical displacement index of the tricuspid ring (TAPSE), by insonating the lateral tricuspid ring in the apical section. The normal value was appreciated greater than $20 \mathrm{~mm}$. The filling ratio of $\mathrm{LV}, \mathrm{E} / \mathrm{e}^{\prime}$ was normally estimated to be 7; between 8 and 12 it was considered gray area with equivocal significance. A value greater than 13 was considered pathological, with the significance of increasing the filling pressure of $\mathrm{LV}$. The relative thickness index (RI) was calculated by relating the radius of the LV cavity to the thickness of the interventricular septum (IVS); a value greater than $0.45 \mathrm{l}$ was considered pathological.

The area of the aortic orifice (AAo) was calculated by means of the mass continuity formula using the software included in the echocardiograph. For this purpose, the apical section 5 chambers was used, obtaining the aortic transvalvular systolic velocities by means of the continuous Doppler technique and the systolic velocities from the LV ejection tract by means of the spectral Doppler technique. The diameter of the ejection tract was obtained using the parasternal longitudinal section, $0.5 \mathrm{~cm}$ proximal to the aortic orifice, through the perpendicular joining the endocardial interface of the interventricular septum and the base of the anterior mitral valve.

The low aortic transvalvular flow was defined by values lower than $35 \mathrm{~mL} / \mathrm{m}^{2}$ of the indexed systolic volume.

The value of the echocardiographic parameters of the patients in the studied group was expressed by the average with the standard deviation of all the obtained values.

The statistical analysis used the Student T test for independent samples in the case of comparisons between groups and the Pearson test to identify the presence of statistical correlations between the followed parameters. Data were expressed as average \pm standard deviation for continuous variables and as a percentage for categorical variables. Statistical calculations were performed using 
SPSS (Statistical Package for the Social Sciences) version 23.0.

\section{Results and discussions}

The presented study, of retrospective observational type, comprises a group of 42 patients with severe degenerative aortic stenosis, referred for ambulatory evaluation by other medical services or hospitalized in the clinics Cardiology and Internal Medicine of the PhD Theodor Burghele Hospital, Bucharest, Romania. The patients with an ejection fraction greater than $50 \%$ were evaluated.

The determination of aortic transvalvular velocities and gradients led to the isolation of two groups of patients: patients with increased transvalvular gradient - group A, which included 22 patients and patients with low transvalvular gradient - group B, consisting of 20 cases.

Regarding the gender distribution, there were predominantly males in both groups, with a slightly higher percentage for females in group $A$. The age limits were between 58 and 88 years, with an average of $71.5 \pm 4.2$ years in group $A$ and between 60 and 87 years, with an average of $72 \pm 3.5$ years in group $B$, the difference being not statistically significant. In terms of age distribution according to gender, there are statistically significant differences for both groups: women of $72 \pm 8$ years vs. men of $67 \pm 6$ years for group $A$, respectively $72 \pm 3.5$ years in women vs. $68 \pm 6$ years in men for group $B$. The average age is higher in women.

The distribution of comorbidities for the two groups was homogeneous: the presence of hypertension was more frequent in group B, $75 \%$ vs. $63 \%$ in group A, but this difference was not statistically significant (fig. I).

The evaluation of the echocardiographic parameters presents comparable values between the two groups

\section{Table 1}

THE DISTRIBUTION OF THE ECOCARDIOGRAPHIC PARAMETRERS IN THE TWO GROUPS (I)

\begin{tabular}{|l|l|l|l|}
\hline Parameter & GROUP A & GROUP B & $\begin{array}{l}\text { Statistical } \\
\text { significance }\end{array}$ \\
\hline PPLV(mm) & $15+-6$ & $15+-6$ & $\mathrm{P}<0.4$ \\
\hline IVSd( mm) & $16+-8$ & $16+-6$ & $\mathrm{P}<0.4$ \\
\hline LVd(mm) & $41+-9$ & $40+-8$ & $\mathrm{P}<0.5$ \\
\hline MM (g) & $240+-10$ & $245+-12$ & $\mathrm{P}<0.07$ \\
\hline MMI (g/m2S) & $120+-9$ & $126+-8$ & $\mathrm{P}<0.07$ \\
\hline RI & $0,67+-0.06$ & $0.66+-0.08$ & $\mathrm{P}<0.5$ \\
\hline Vol. LA (ml) & $78+-6$ & $77+-8$ & $\mathrm{P}<0.4$ \\
\hline MAPSE(mm) & $14+-2$ & $11+-3$ & $\mathrm{P}<0.005$ \\
\hline TAPSE(mm) & $19+-3$ & $18+-2$ & $\mathrm{P}<0.4$ \\
\hline
\end{tabular}

Legend: Group A = with increased aortic systolic transvalvular gradient; Group $B=$ with low systolic aortic transvalvulargradient; $P W L V d=$ diastolic thickness of the posterior wall of the LV; IVSd = diastolic thickness of the interventricular septum; $L V d=$ diastolic diameter of the LV cavity; $M M=$ myocardial mass; $M M I=$ myocardial index, so myocardial $R I=$ relative thickness index; $L A$ volume = left atrial volume; MAPSE = apical displacement of the lateral mitral ring; TAPSE = apical displacement of the lateral tricuspidian ring; statistically significant if $p<0.05$ 
compared to $13 \pm 2$ for group $B$. The aortic valvular echocardiographic parameters were comparable between the two groups for opening the cusps and the orifice area: group $A 9.01 \pm 1.06$ vs. $8.9 \pm 0.7$ group $B$, respectively $0.80 \pm 0.05 \mathrm{~cm}^{2}$ group A vs. $0.79 \pm 0.07 \mathrm{~cm}^{2}$ group $B$ (Table 2). Significant and statistically significant differences were recorded between the two groups $A$ and $B$ for: aortic systolic velocity $4.3 \pm 0.9 \mathrm{~m} / \mathrm{s}$, respectively $3.1 \pm 0.8 \mathrm{~m} / \mathrm{s}$, maximum aortic transvalvular gradient $73.9 \pm 19 \mathrm{mmHg}$, respectively $37 \pm 12 \mathrm{mmHg}$ and medium transvalvular gradient $46 \pm 16 \mathrm{mmHg}$, respectively $26 \pm 9.5 \mathrm{mmHg}$.

The statistical analysis evaluated the existence of possible correlations between the area of the aortic orifice and the echocardiographic parameters used to estimate the severity of the aortic stenosis with preserved EF and low gradient. Direct correlations expressed by the Pearson coefficient $r$ with all the analyzed parameters were identified. The strongest correlations, corresponding to the highest values of the coefficient $r$, were established between the area of the aortic orifice and: the amplitude of the valve opening $(r=0.87)$, the ratio of filling of the left ventricle E/e' $g(r=-0.85)$, diastolic thickness of the posterior wall of the left ventricle PWLVd $(r=0.78)$, the tissue mitral protodiastolic velocity of the left ventricle $(r=0.76)$, the systolic thickness of the left ventricular septum SILVs $(r=0.73)$. Direct positive correlation was also established between the aortic orifice area and: spectral mitral telediastolic velocity $A(r=0.42)$ and the volume of the left atrium VolLA $(r=0.42)$, but the coefficient values are low.

In the studied group the prevalence of cases of severe degenerative aortic stenosis with high EF and increased gradient is relatively higher (52\%) compared to the cases with low gradient (48\%). This distribution is different from the data published in the literature [22-24], which estimates a predominance of approximately $20 \%$ of the forms with low gradient and retained ejection fraction.

Gender distribution of aortic stenosis for both groups has a male predominance, a valid ascertainment also in the literature. This distribution is slightly more pronounced for the cases with high gradient in group $A$.

A particular aspect, valid for both groups, is the lower average age for men compared to women. Although the average age of patients coincides with that reported in published studies, the lower average age of men could be partly explained by the more frequent association of genotype I of clinical expression of aortic stenosis.

The assessment of the severity of DAS by the echocardiographic technique faces in real life with complex difficulties. Thus, a first aspect is represented by the limits imposed sometimes by the transthoracic technique: the difficult ultrasound window, the imperfect alignment of the ultrasound beam to the direction of the transaortic systolic blood flow and, consequently, the imprecise detection of the maximum velocities at the level of the aortic orifice. To these can be added the incorrect placement of the volume sample in the ejection tract and the failure to comply with the standards for correct measurement of its diameter. The conditions listed are some of the most common causes for which some authors believe that this form of aortic stenosis with preserved ejection fraction and low flow called a paradoxical lowflow low-gradientaortic stenosis may in fact be a technical artifact. [26] The explanation of the increased frequency of this form in our study, compared to the data published in the literature, could be represented by the evaluation of all hospitalized patients with aortic stenosis and those referred by other medical services, known or not with this condition. Studies in the literature do not always specify the methodology of recruiting the patients included in the study. Also, the explanation of this phenomenon may also contribute to the fact that the patients in the study were evaluated completely from the point of view of severity, including the calculation of the area of the aortic orifice. Studies in the literature related to the evaluation of aortic stenosis severity are numerous, but a significant number of them use only the maximum and average systolic velocities and gradients for diagnosis and monitoring of evolution, so that a considerable percentage of this particular form could be underdiagnosed.

The generally accepted main mechanism for the explanation of low blood flow and transvalvular gradient in the presence of the preserved ejection fraction [30] is considered to be severe concentric left ventricular hypertrophy which associates a reduced cavity and therefore a low systolic flow. In the presented group, for both forms of stenosis, with high and low gradient, the indexed myocardial mass, the thickness of the LV walls and the size of the cavity have comparable values, which suggests the possibility of additional mechanisms.

A possible mechanism [46] mentioned in the literature, which could be implicated in the existence of the low transvalvular gradient, is the presence of a rigid aortic ring that contributes to the decrease of the systolic flow. From this perspective, the definition of aortic stenosis previously mentioned [1] emphasizes the role of the ejection tract and, therefore, of the aortic ring in the occurrence of valvular obstruction.

Another mechanism invoked in explaining the low gradient of this paradoxical form is the decrease of the systolic longitudinal function in the subendocardial area. This finding is supported by the spackle tracking technique, which has shown a decrease in deformation and deformation rate of myocardial fibers in this region [47].

This explanation also seems to be confirmed by the results of our study. The parameters of longitudinal systolic function of LV, MAPSE and mitral tissue velocity $s L V$, show low values for the subgroup with low systolic transvalvular gradient, suggesting the onset of longitudinal systolic dysfunction of LV. The low value of MAPSE for group $B$ is statistically significant.

In our study, an interesting aspect is the more frequent presence of hypertension in the group with low transvalvular gradient, although the difference from the group with increased gradient is not statistically significant. It is possible that high blood pressure is, according to some data from the literature, [48] an excess of post-pregnancy, afterload excess, resulting in the incipient depression of contractility, as the results of our study suggest.

Another possible explanation for the existence of this low gradient in severe aortic stenosis with preserved EF could be the existence of a fixed or functional obstruction in the ejection tract or the LV cavity. Thus, in our group we have identified several cases that can influence the precise interpretation of the systolic velocities in the LV ejection tract. Thus, a case is represented by the detection of an intraventricular systolic velocity that generates a gradient in the medioventricular area and not at the level of the ejection tract, where the speeds required for the calculation are interrogated. From this point of view, the current protocols for assessing the severity of DAS signal the limitations of the method in the presence of a speed greater than $1.2 \mathrm{~m} / \mathrm{s}$ in the ejection tract of the LV. This context could often be overlooked and in order to avoid it, it would be advisable to carefully examine the entire ventricular cavity during the systole, starting with the apical area. We interpreted the possible intraventricular gradient in the context of concentric hypertrophy of LV, with the 
significance and consequences of a functional obstacle. A second case is the existence of an aberrant membranous tract at the mediapical level of the LV cavity, which could be considered a mechanical obstacle in filling and emptying the LV cavity. Although normally an intracavitary membranous tract does not affect hemodynamics, in the case of major concentric hypertrophy associated with a reduced cavity, its existence could alter the filling and evacuation of LV. In daily practice, the ventricular cavity insonation could omit the detection of these obstacles due to the limit imposed, not infrequently, by the difficulty of the ultrasound window.

\section{Conclusions}

Severe degenerative aortic stenosis with preserved ejection fraction presents at the echocardiographic evaluation different values of the transvalvular gradient. Excluding technical artifacts, some useful conclusions are drawn from our study in clinical practice regarding the paradoxical low-flow low-gradientform. We also mention that, although our study includes a small number of patients, for a robust statistical conclusion, we advance some preliminary conclusions. A first conclusion refers to the increased preponderance of men with DAS, regardless of the value of the transvalvular gradient and their younger age compared to women. The second conclusion regarding the low gradient shape is the increase of the E/e' ratio of the $L V$, suggesting the increase of filling pressures for this particular form of DAS with retained EF. Another conclusion would be the direct but negative correlation between the area of the aortic orifice and the increase of the filling ratio $\mathrm{E} / \mathrm{e}^{\prime}$, and related to it, the onset of the systolic LV dysfunction suggested by the low value of the spectral and tissue systolic indices.

The main purpose of this study is to identify the optimal time for the formulation of the indication of valve replacement in patients with severe DAS and preserved ejection fraction, independent of the existence of symptoms $[13,14]$. According to the data published in the literature $[13,14,17,20,28,29]$ the postoperative evolution and survival is optimal for patients with preserved EF and increased gradient and significantly reduced for those with low gradient $[28,29]$. For this form, which was the object of our study, the identification of the optimal early moment, suggested by the subclinical installation of the systolic dysfunction could lead to the improvement of the postoperative prognosis.

\section{References}

1.OTTO, C., PRENDERGAST, B., The New England Journal of Medicine 2014; 371, p:744-56.

2.KURTZ, C., OTTO, C.,. Medicine 2010; 89, p:349-379

3.INNASIMUTHU, AL., KUMAR, S., LAZAR, J., KATZ, WE., Texas Heart Institute J ournal 2014; 41, p:273-27

4.MANN, D., ZIPES, D., LIBBY, P., BONOW, R., Braunwald's Heart Disease -A textbook of cardiovascular medicine, 10 th Edition, single volume, Elsevier Saunders, Philadelphia, 2014

5.YETKIN, E., WALTENBERGER, J., International Journal of Cardiology 2009; 135, p:4-13

6.BECKMANN, E., GRAU, JB., SAINGER, R. et al., Journal of Valvular Heart Disease 2010; 19, $p$ :441-452

7.RAJ AMANNAN, NM., Expert Revue of Cardiovascular Therapy 2004; 2, $p: 845-854$

8.PARISI, V., LEOSCO, D., FERRO, G. et al., Nutrition .Meyabolism \&Cardiovascular Disease 2015; 25, p:519-525

9.BOUDOULAS, KD., WOLFE, B., RAVI, Y. et al., J ournal of Cardiology 2015; 65, p:377-382
10.IANOSI, ES., DANTES, E., CSIPOR, A., SZATHMARY, M., SOCACI, A., RUSU, E., NEMES, R.M., Rev. Chim. (Bucharest), 69, no. 10, 2018, p:2725-2727

11.IANOSI, E.S, POSTOLACHE, P, MACOVEI, LA, SZATHMARY, M, SZASZ, S, NEMES, R.M, JIMBOREAN, G., Rev. Chim. (Bucharest), 69, no. 7, 2018, p:1766-1769

12.MIURA, S., ARITA., T., KUMAMARU, $H$. et al., J ournal of Cardiology 2015; 65, p:353-359

13.TANIGUCHI,T., MOROMOTO, T., SHIOMI, H., J ournal of the American college of Cardiology 2015; 66, p:2827-2838.

14.OTTO, CM., KUMBHANI, DJ ., ALEXANDER, KP. et al., J Am Coll Cardiol, 2017, 69(10), p: 1313- 1346.

15.PIBAROT, P., DUMESNIL JG., Journal of American College of Cardiology 2012; 60, p:169-80

16.TANDON, A., GRAYBURN, PA., Journal of American College of Cardiology -Cardiovascular Imaging 2013; 6, p:184-195

17.CZARNY, MJ ., RESAR, JR., Clinical Medicine Insights:Cardiology; 8(s1), p:15-24.

18.ELEID, MF., MANKAD, S., SORAJJA, P. Heart Failure Revue 2013; 18, p:1-14.

19.CHIN CW, VASSILIOU V, J ENKINS WS, PRASAD SK, NEWBY DE, DWECK MR., Expert Rev Cardiovasc Ther. 2014; 12(7), p:901-12 20.DAHL, JS., ELEID, MF., MICHELENA, HI., Circulation Cardiovascular Imaging 2015; 8, p:1-8

21.*** ESC CLINICAL PRACTICE GUIDELINES, European Heart] ournal 2017; 38, p:2739-2791.

22.PIBAROT, P., DUMESNIL JG., Journal of American College of Cardiology 2012; 60, p:1845-53

23.PIBAROT, P., DUMESNIL JG., Journal of the American College of Cardiology 2011; 58, p:413-415

24.PIBAROT, P., CLAVEL, MA., Journal of American College of Cardiology.2015; 65, p:67-71

25.BAUMGARTNER H., J ournal of American Colege of Cardiology 2012; 60, p:1268-1270

26.VALENCIA-SERRANO, F., BUSTOS, DSB., CABEZA, AP., Journal of American College of Cardiology 2015; 65, p:1981-1987

27.HERRMANN,S., STORK, S., NIEMANN, M. et al., J ournal of American College of Cardiology 2011; 58, p:402-412

28.CLAVEL, MC., DUMESNIL, JG., CAPOULADE, R. et al., .j ournal of American College of Cardiology 2012; 60, p:1259-67

29.YAMASHITA E., TAKEUCHI, M., SEO Y. et al., J ournal of Cardiology 2015; 65, p:360-368.

30.BARTEL, T., MULLER, S., European Heart Journal 2013; 34, p:18621863

31.CONSTANTIN, D.A., CIORICEANU, I.H, TANTU, M.M, POPA, D., BADAU, D., BURTEA, V., NEMET, G.C., ROGOZEA, L.M., Rom J Morphol Embryol, 2017, 58(3), p:1121-1125

32.POPESCU IG, SECHEL G, LEASU FG, TANTU, MM, COTOI GG, ROGOZEA LM, Rom J Morphol Embryol 2018; 59(3), p:1001-1005.

33.IORDACHE PD., MATES D., GUNNARSSON B. et al., J Cell Mol Med. 2018; 22(12), p:6068-6076.

34. IVAN, V.S., ALBULESCU, N., ALBULESCU, I.R., APOSTOL, A., BUZAS, R., SCHILLER, A., TIMAR, R., LIGHEZAN, D., IVAN, M.V., Rev. Chim. (Bucharest), 70, no. 4, 2019, p. 1479-1484

35.NEMES, R.M., POP, C.S., CALAGIU, D., DOBRIN, D., CHETROIU, D., JANTEA, P., et al. Revista medico-chirurgicala a Societatii de Medici si Naturalisti din lasi. 2016;120(1), p:34-39.

36.BUSE, A.M., NANEA, I.T., NICOLAE, C. et al., Rev. Chim. (Bucharest), 70, no. 5, 2019, p:1738-1743

37.GOLLI, A.L., NITU, F.M., BALASOIU, M., et al., Rev. Chim. (Bucharest), 70, no. 5, 2019, p:1778-1783

38.AVRÃMOIU, I., PETRESCU, IO., CIUREA, M.E, et al., Rom J Morphol Embryol, 2016; 57(3), p:943-950

39.DIACONESCU, DE., DIMA, L., MARINESCU, DM., TANTU, MM., ROGOZEA, LM., Rom J Morphol Embryol, 2014, 55(4), p:1371-1375

40.TANTU, MM., MAN, G.M., ROGOZEA, L.M. et al., Rom J Morphol EMBRYOL 2018, 59(3), p:895-902 
41.TANTU, M.M., MAN, G.M., PAUnesCU, A.,. et al., Rev. Chim. (Bucharest), 70, no. 4, 2019, p:1307-1310

42.DUCEAC, L.D., TARCA, E., CIUHODARU, M.I., TANTU, M.M., et al., Rev. Chim. (Bucharest), 70, no. 1, 2019, p: 199-201

43.PLESA, C.F., NICOLAE, C., SIRBU, C.A., NEMES, R., PAUNESCU, A., TANTU, M.M., Farmacia, 67, 2019, p: 27-33

44.TANTU, M.M, MAN, G.M, PAUNESCU, A., et al., Rev.Chim. (Bucharest), 69, no. 11, 2018, p:3001-3005

45. *** AMERICAN SOCIETY OF ECHOCARDIOGRAPHY AND THE EUROPEAN ASSSOCIATION OF CARDIOVASCULAR IMAGING. J ournal of American Society of Echocardiography 2015; 28, p:1-39.
46.NANEA, IT., New Approaches to Aortic Diseases from Valve to Abdominal Bifurcation, 1st Edition, Academic Press, Tintoiu I., Elefteriades, J., Ursulescu A., Underwood M., Droc I., 2017, p:133-143 47.VAN DALEN BM, TZIKASA, SOLIMAN OI, HEUVELMAN HJ, VLETTER WB, TEN CATE FJ, GELEIJ NSE ML., Echocardiography. 2013, 30(3), $\mathrm{p}: 293-300$

48.0TTO, C., BONOW, R., Valvular Heart Disease: A Companion to Braunwald's Heart Disease E-Book, 4th Edition, Elsevier Saunders, Philadelphia, 2012

Manuscript received: 9.06 .2019 